\title{
Deslocamento espacial e temporal da linha de costa nas praias pertencentes a Recife e Jaboatão dos Guararapes, Pernambuco, Brasil ${ }^{*}$
}

\author{
Luciana Maria Da Silva** \\ Milde Maria Da Silva Lira***
}

Recebido 4 de junho de 2017; aceito 6 de novembro de 2017

\section{Resumo}

Nas últimas décadas, o crescimento da urbanização vem provocando grandes transformações nos aspectos sociais, econômicos e morfológicos nas áreas costeiras. As praias urbanas de Boa Viagem e Pina (Recife-PE) e a praia de Piedade (Jaboatão dos Guararapes-PE) têm apresentado estes aspectos, onde se observa vulnerabilidade costeira à erosão. O objetivo deste trabalho é analisar o deslocamento espacial e temporal da linha de costa. Para isto modelou-se a massa de dados obtida do método de levantamento geodésico relativo cinemático, o qual possibilita o monitoramento da linha de costa, para os anos de 2007, 2009, 2010 e 2012. Foi empregado o método de transectos, o qual é necessário adotar uma linha de costa como base, 2007. E foi dividida a área de estudo em 6 setores para que se pudesse analisar o deslocamento médio da linha de costa. Os setores 1 e 5 apresentam acreção em todos os períodos analisados (2007-2009, 2007-2010, 2007-2012). O setor 2 apresentou erosão em todos os períodos analisados. Os setores 3 e 6 nos períodos de 2007-2009 e 2007-2010, apresentaram erosão, enquanto de 2007-2012 apresentaram tendência a acreção. Destacase que no setor 4 não se realizou o cálculo devido ser a área que apresenta enrocamen-

* Este artigo é apresentado a partir dos resultados da Dissertação de Mestrado, intitulada: Modelagem Fuzzy como subsidios para a especialização da vulnerabilidade costeira a erosão, defendida em 31 de janeiro de 2013.

** Universidade Federal de Pernambuco, Departamento de Engenharia Cartográfica, Universidade Federal do Paraná, Departamento de Geomática. Correspondência Rua Luiz Porfírio Pessoa 43, Centro, Timbaúba-PE, Brasil, e-mail: lumasilva15@gmail.com.

*** Universidade Federal de Pernambuco, Departamento de Engenharia Elétrica. Correspondência Av. Prof. Moraes Rego 1235, Cidade Universitária, Recife-PE, Brasil, e-mail: milde@ufpe.br. 
to. Esse estudo tende a contribuir para análise do comportamento temporal nos projetos de tomadas de decisões em ambientes costeiros.

Palavras chave: crescimento da urbanização, monitoramento da área costeira, vulnerabilidade à erosão, Pernambuco, GPS.

\title{
Resumen
}

En las últimas décadas, el crecimiento de las urbanizaciones viene provocado grandes transformaciones en los aspectos sociales, económicos y morfológicos en las áreas costeras. Las playas urbanas de Boa Viagem y Pina (Recife-PE) y la playa de Piedad (Jaboatão dos Guararapes-PE) han presentado estos aspectos, donde se observa vulnerabilidad costera a la erosión. El objetivo de este trabajo es analizar el desplazamiento espacial y temporal de la línea de costa. Para ello se modeló la masa de datos obtenida del método de levantamiento geodésico relativo cinemático, el cual posibilita el monitoreo de la línea de costa, para los años de 2007, 2009, 2010 y 2012. Se empleó el método de transectos, el cual es necesario adoptar una línea de costa como base, 2007. Y se dividió el área de estudio en 6 sectores para que se pudiera analizar el desplazamiento medio de la línea de costa. Los sectores 1 y 5 presentan acreción en todos los períodos analizados (2007-2009, 2007-2010, 2007-2012). El sector 2 presentó erosión en todos los períodos analizados. Los sectores 3 y 6 en los períodos 2007-2009 y 2007-2010, presentaron erosión, mientras que de 2007 a 2012 presentaron tendencia a la acreción. Se destaca que en el sector 4 no se realizó el cálculo debido a que el área presenta una escollera. Este estudio tiende a contribuir para el análisis del comportamiento temporal en los proyectos de toma de decisiones en ambientes costeros.

Palabras clave: crecimiento de la urbanización, monitoreo del área costera, vulnerabilidad a la erosión, Pernambuco, GPS.

\begin{abstract}
In recent decades, the growth of urbanization has caused great transformations in the social, economic and morphological aspects in the coastal areas. The urban beaches of Boa Viagem and Pina (Recife-PE) and the beach of Piedade (Jaboatão dos Guararapes-PE), have presented these aspects, where coastal vulnerability to erosion is observed. The objective of this work is to analyze the spatial and temporal displacement of the shoreline. For this, the several data obtained from the kinematic relative geodetic survey method was modeled, which allows the monitoring of the shoreline for the years 2007, 2009, 2010 and 2012. The method of transects was used, which is necessary to adopt a shoreline as base, year 2007. The study area was divided into 6 sectors to analyze the average displacement of the shoreline. Sectors 1 and 5 presented accretion in all periods analyzed
\end{abstract}


(2007-2009, 2007-2010, and 2007-2012). Sector 2 presented erosion in all periods analyzed. The sectors 3 and 6 in the periods 2007-2009 and 2007-2010, presented erosion, while from 2007-2012 they presented the tended to accretion. Stand out that in sector 4 the calculation was not made due to the fact that it is the area that presents rockfill. This study tends to contribute to the analysis of temporal behavior in decision-making projects in coastal environments.

Key words: advance of urbanization, coastal area monitoring, vulnerability to erosion, Pernambuco, GPS.

\section{Área de estudo}

Recife, conforme dados do censo de 2010, conta com uma população de 1.537 .704 habitantes e apresenta uma superfície territorial de 218,498 $\mathrm{km}^{2}$, com 7.037,6 $\mathrm{hab} / \mathrm{km}^{2}$. Limitando-se ao norte com as cidades de Olinda e Paulista, ao sul com o município de Jaboatão dos Guararapes, a oeste com São Lourenço da Mata e Camaragibe, e a leste com o Oceano Atlântico. Jaboatão dos Guararapes conforme dados do censo de 2010, conta com uma população de 644,620 habitantes, apresenta uma superfície territorial de 258,566 km², com 2.493,06 hab $/ \mathrm{km}^{2}$. Limitando-se ao norte com o município de Recife, ao sul com o município de Cabo de Santo Agostinho, a oeste com as cidades de São Lourenço da Mata e Moreno, e a leste com o Oceano Atlântico. O município na área fluvial recebe influência das Bacias Hidrográficas do Rio Jaboatão, Rio Pirapama e Tejipió. Além de possuir a maior lagoa estuarina (Lagoa Olho D’água) na área urbana do estado do Estado de Pernambuco (Da Silva, 2013). Segundo Aureliano (2000) a caracterização da ocupação do município se deu através de loteamentos residenciais, industriais e comerciais, sendo que, nas últimas décadas, houve uma grande ascensão na construção de edifícios, condomínios e hotéis ao longo da orla.

Segundo Manso et al., (2006), o litoral pernambucano foi delimitado e setorizado com base na sua situação geográfica e política em 21 municípios, distribuídos numa faixa de $187 \mathrm{~km}$, que se estende desde o município de Goiana, ao norte, até o município de São José da Coroa Grande, ao sul. A costa pernambucana apresenta baixa altitude, chegando a atingir, em vários pontos, altitudes inferiores ao nível médio do mar. A Figura 1 apresenta um mapa de localização do Estado de Pernambuco na Região Nordeste do Brasil, a ampliação do Estado, e os municípios de Recife e Jaboatão dos Guararapes e em particular uma imagem de satélite que define as praias do Pina, Boa Viagem e Piedade.

O Recife tem um litoral formado pelas praias do Pina e Boa Viagem que totalizam aproximadamente 8,5 km de linha de costa, enquanto Jaboatão é formado pelas praias de Barra da Jangada, Candeias e Piedade que totalizam aproximadamente 8 km, conforme mostra a Tabela 1 com a extensão litorânea das praias. 

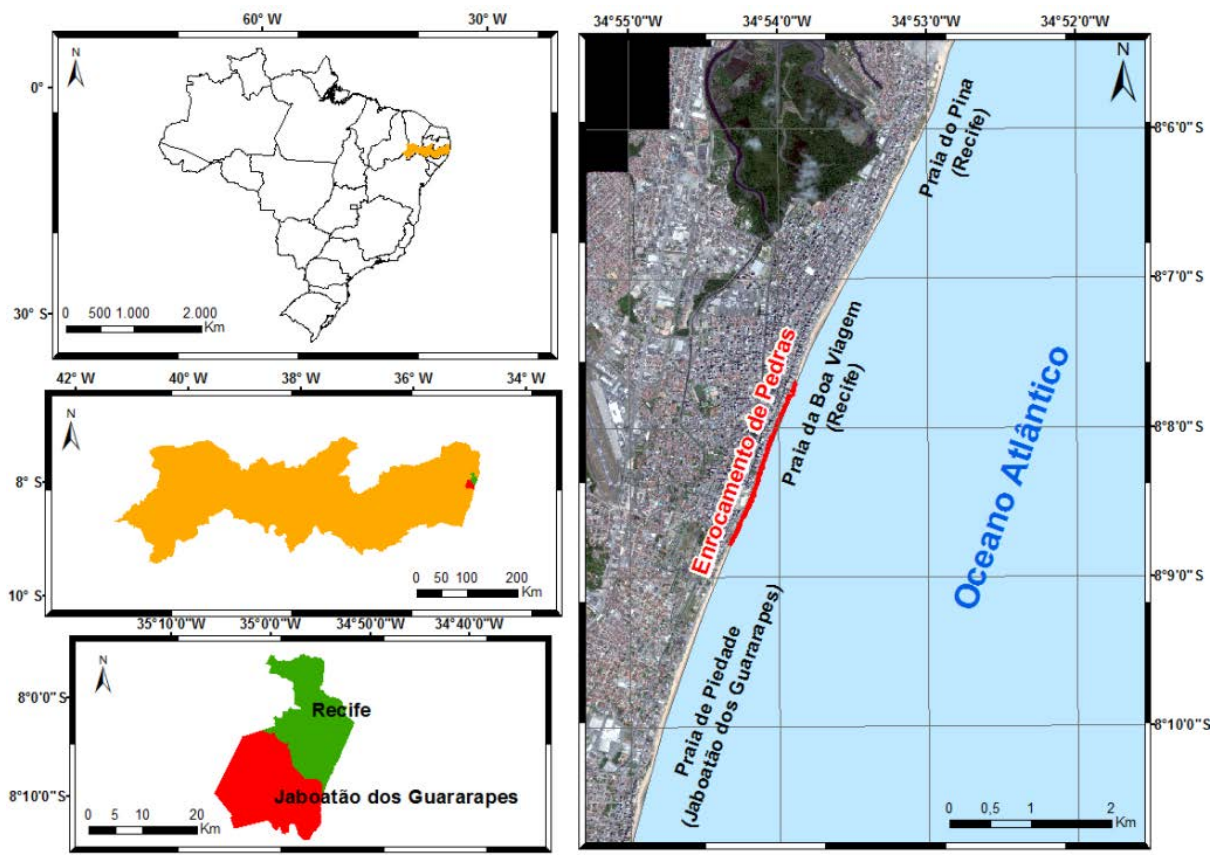

Figura 1. Mapa de Localização da Área de Estudo: Praia de Piedade (Jaboatão dos Guararapes) Praia do Pina e da Boa Viagem (Recife).

Tabela 1

Faixa Litorânea de Recife e Jaboatão dos Guararapes

\begin{tabular}{lc}
\hline \multicolumn{1}{c}{ Praias } & Faixa Litorânea $(\mathrm{km})$ \\
\hline Boa Viagem & 7,38 \\
Pina & 1 \\
Barra de Jangada & 0,4 \\
Candeias & 3 \\
Piedade & 4,5 \\
\hline
\end{tabular}

Fonte: Da Silva et al. (2012). 


\section{Ambiente praial e linha de costa}

O ambiente praial, segundo Komar (1998) pode ser dividido em quatro partes: dunas, pós-praia, praia média (estirâncio) e ante praia. As praias são definidas como um ambiente sedimentar costeiro de composição variada, formadas mais comumente por areia, e condicionadas pela interação dos sistemas de ondas incidentes sobre a costa (King, 1959). Segundo Da Silva (2013), a praia seria o trecho que se limita as ondas vindas de mar aberto, próxima à linha de costa, ou seja, é a maior posição que as ondas podem chegar em época de tempestades.

Segundo Boak e Turner (2005); Almeida (2008); Rocha et al. (2008), a linha de costa é considerada como uma das feições geomorfológicas mais dinâmicas do nosso planeta e o seu monitoramento é necessário para dar suporte ao gerenciamento costeiro. Em um ambiente costeiro verifica-se em vários locais o processo de erosão costeira, resultado da combinação de fatores naturais como: tempestades, correntes marítimas, mudanças sazonais além da ação humana (explorações costeiras e as atividades de engenharia) (Rocha et al., 2008; Harley et al., 2011; Emm et al., 2016).

O monitoramento costeiro vem se beneficiando do estado da arte do GNSS onde um dos grandes desafios é aplicar um método de posicionamento para obtenção precisa de feições costeiras relacionadas a um determinado instante de tempo (Da Silva et al., 2013). Em muitos estudos costeiros a falta de informação cartográfica temporal pode gerar dificuldade no diagnóstico de uma determinada área, sendo muito comum em modelagens costeiras a combinação de informações de distintas fontes.

A partir da década de 60, as praias da Boa Viagem e Pina localizadas no município do Recife-PE e as praias de Barra de Jangada, Candeias e Piedade localizadas no município de Jaboatão dos Guararapes-PE vêm sendo urbanizadas próximo à linha de costa. Diante das construções cada vez mais sobre a pós-praia e até mesmo do estirâncio, observam-se problemas de vulnerabilidade à erosão costeira (Da Silva et al., 2013). Esses processos dão origem às praias urbanas que, segundo Smith (1991), são aquelas que circundam cidades, bairros ou balneários consolidados de diversos níveis de desenvolvimento. Ou seja, são as praias sob ocupação desordenada que interferem em processos naturais podendo causar erosão. Em um estudo realizado por Araújo et al. (2007) foi possível analisar a ocupação urbana das praias de Pernambuco, onde no setor Metropolitano do Estado apresentou 47\% de sua extensão indicando a ocupação concomitante da pós-praia e do estirâncio.

O objetivo deste estudo foi determinar a evolução multitemporal, ao longo de 5 anos, a partir da taxa de variação da linha de costa obtendo assim sua acreção ou erosão nas praias do Pina, da Boa Viagem e de Piedade. Devido ao processo erosivo decorrente nestas praias com a urbanização presente próxima a linha de costa, buscou-se realizar esta análise para fins de monitoramento da posição da linha de costa, 
pois uma forma de realizar um gerenciamento eficiente é investir no monitoramento geodésico da linha de costa, que desempenha um papel essencial no planejamento territorial. Esses resultados foram desenvolvidos na dissertação de mestrado de Da Silva (2013).

\section{Vulnerabilidade à erosão costeira e o surgimento dos enrocamentos}

O problema da erosão costeira é um processo natural que pode ter causas antrópicas, podendo se tornar um problema quando da perda de patrimônios, por exemplo, Morais et al. (2008) relatam que nos estudos do problema da erosão costeira na linha de costa em Maceió, os imóveis localizados nos primeiros 50 metros desvalorizaram-se economicamente.

A zona costeira concentra grande potencial econômico e turístico que por sua importância a Lei de Gerenciamento Costeiro do Estado de Pernambuco (LGCEP) (2010) que trata dos instrumentos e ocupação da zona costeira em seu capítulo V, artigo 10 inciso $2^{\circ}$, propõe que para as áreas urbanizadas não serão permitido qualquer tipo de instalações de novas construções, urbanização ou outra forma de utilização do solo na zona costeira, na faixa de 33m (trinta e três metros), considerada como non aedificandi, ou valor superior a este quando comprovado em estudo técnico, medidos perpendicularmente em direção ao continente, a partir da linha de preamar máxima da sizígia atual. Ao longo do litoral de Boa Viagem e Piedade é possível observar novas obras muito próxima ao mar demonstrado que a urbanização costeira continua em plena atividade.

Como apresentado por Da Silva et al. (2013), a vulnerabilidade à erosão costeira está associada a diversos processos morfodinâmicos assim como antrópicos, onde se pode utilizar uma ampla gama de métodos para analisar o grau de vulnerabilidade. As recentes pesquisas têm apresentado que um determinado conjunto utilizando dados qualitativos e quantitativos pode-se desenvolver métodos para análise da vulnerabilidade costeira à erosão. Para as variáveis são atribuídos pesos proporcionais a influência da vulnerabilidade em um modelo analítico objetivando gerar índices numéricos que resultam em mapas temáticos temporais da vulnerabilidade ao longo de uma área costeira, como pode ser visto em Mazzer et al. (2008); Mallmann e Araújo (2010); Raposeiro e Ferreira (2010), Da Silva (2013), Da Silva et al. (2013) e Mendonça et al. (2014).

Nos últimos anos, esforços vêm sendo feitos para identificar as áreas mais vulneráveis para posterior monitoramento e detalhamento das razões dos desequilíbrios observados (Muehe, 2006). Segundo Daniel (2001) o problema da vulnerabilidade à erosão não consiste em tempestades ou do nível do mar e sim na questão dos seres humanos localizarem suas casas, estradas e diques ao longo do litoral bloqueando toda a área de recreação e assim o estreitamento da praia. Detalhes da recreação da área costeira podem ser visto em Gonçalves et al. (2013). 
A erosão praial é um problema sério que ocorre em vários lugares do mundo podendo alcançar estágios bastante crítico, assim como ocorre ou ocorreu em outras praias no mundo e no Brasil, por exemplo, na Espanha, em trechos do litoral, a urbanização não deixou espaço suficiente para dinâmica costeira ocasionando prejuízos ambientais, comerciais e recreativos (Doody, 2001). No estado de Delaware, localizada na costa leste dos Estados Unidos o enorme valor das propriedades ao longo da costa e o valor econômico da indústria do turismo costeiro combinam para criar um problema de gestão de recursos naturais que é particularmente difícil de resolver, pois na medida em que a indústria do turismo nessa área se expande, há o aumento de barreiras para evitar o avanço do mar devido à erosão das praias (Daniel, 2001).

Os enrocamentos ou barreiras costeiras são utilizados em locais com o intuito de proteger o continente contra as forças do vento, ondas e marés (Neves e Muehe, 2008), mas normalmente as praias que tem essas barreiras construídas são as que estão bastante vulneráveis à erosão, pois geralmente nos locais onde havia dunas ou vegetação dão lugar a essas barreiras.

Diversos estudos vêm buscando formas de combater a erosão costeira, por exemplo, Ryabchuk et al. (2010) apresentam um estudo de longo e curto prazo dos problemas da erosão costeira ao longo da linha de costa no leste do Golfo da Finlândia. Hapke e Plant (2010) apresentam um modelo probabilístico Bayesiano para tentar prever a erosão costeira do penhasco ao norte de San Diego, Califórnia onde verificaram se o aumento gradual do nível do mar ou grandes eventos de tempestade, entre outras pesquisas.

\section{Métodos}

\section{Levantamento Temporal da Linha de Costa}

A Figura 2 mostra o trecho percorrido no levantamento relativo cinemático na área de estudo que compreende as praias do Pina, da Boa Viagem e Piedade, localizadas no ambiente litorâneo das cidades do Recife e Jaboatão dos Guararapes, no Setor Médio da costa pernambucana, com um formato alongado, na direção N-S.

Os dados de levantamentos geodésicos da linha de costa na área de estudo são oriundos de um espaço amostral de $t$ anos contendo quatro amostras: 2007, 2009, 2010 e 2012. Em todos os levantamentos geodésicos foram utilizados o método de levantamento geodésico relativo cinemático, onde o receptor base ficou instalado em um local conhecido como terceiro jardim na Avenida Boa Viagem sobre um marco geodésico da prefeitura do Recife com coordenadas precisas conhecidas.

O nível de precisão do método de levantamento cinemático relativo com pósprocessamento é em torno de $10 \mathrm{~cm}$ podendo alcançar poucos centímetros caso as condições sejam favoráveis (cobertura de satélites, ausência de multicaminho, distância até a base no processamento, etc.) (Seeber, 2003). 


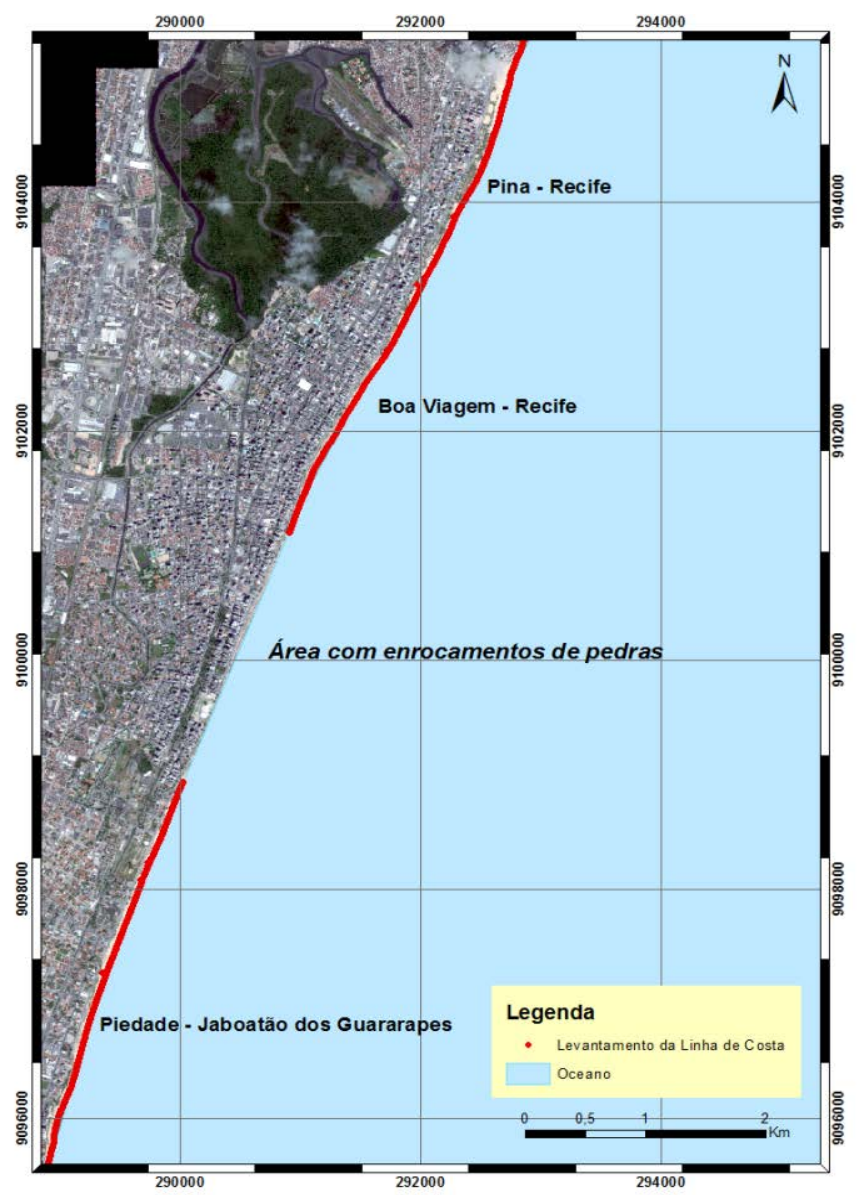

Figura 2. Trecho pecorrido no levantamento relativo cinemático, o qual compreende as praias da Boa Viagem e do Pina (Recife) e a praia de Piedade (Jaboatão dos Guararapes), e sem demarcação a área com enrocamento de pedras construído por processo antrópico.

\section{Divisão Setorial da Área de Estudo}

Para uma melhor compreensão da análise do deslocamento da linha de costa e do uso do solo dividiu-se em setores segundo o comportamento da região da pós-praia do ambiente praial. O parâmetro distância em metros foi utilizado para caracterizar a proximidade de um setor as áreas urbanizadas ou com a presença de enrocamentos.

O Setor 1 que se inicia no fim do enrocamento de Brasília Teimosa (Praia do Pina) e segue em direção sul com uma extensão de $3060 \mathrm{~m}$, até um canal de escoamento de águas, na altura do edifício Canopus no 2594 da Avenida Boa Viagem (Figura 3). 

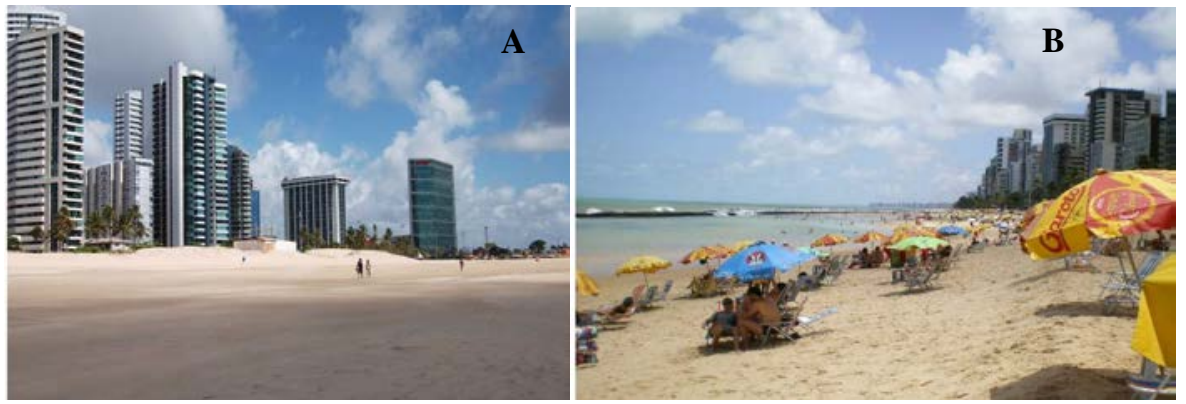

Figura 3. A) Apresenta uma área da praia do Pina com uma ampla pós-praia. B) Apresenta uma área da praia da Boa Viagem do Norte para o sul, onde se observa estreitamento da faixa de areia.

Fonte: Da Silva (2013).

Este setor é caracterizado por uma pós-praia bem desenvolvida, com a presença de dunas e com uma distância entre a linha de costa e o primeiro obstáculo urbano entre 120 e 40 metros. No Terceiro Jardim da Av. Boa Viagem, verifica-se ocupação urbana na região da pós-praia (benfeitorias de lazer). Ao percorrer para a direção sul observa-se que a pós-praia torna-se mais estreita e apresenta uma diminuição da presença das dunas frontais, descrições importantes para análise da vulnerabilidade. O Setor 2 no centro da praia da Boa Viagem, inicia-se no final da das dunas frontais depois do Terceiro Jardim da Avenida Boa Viagem e segue para o sul com uma extensão de 1485 m até o cruzamento da Av. Boa Viagem com a rua Bruno Veloso (Figura 4).
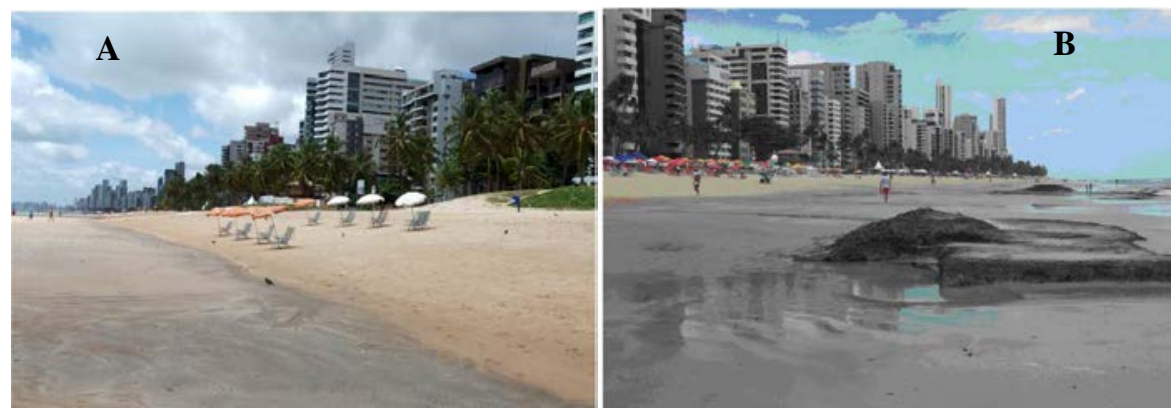

Figura 4. A) Apresenta uma área com inclinação maior na face praial. B) Apresenta o estreitamento do ambiente praial e a presença de beachrocks.

Fonte: Da Silva (2013).

Este setor se caracteriza por uma pós-praia sem a presença de dunas e sem vegetação rasteira, mas sem ocorrência de erosão costeira, e com uma distância média entre a linha de costa e o primeiro obstáculo urbano de aproximadamente 40 metros. 
O Setor 3 ao norte do início do enrocamento da praia da Boa Viagem, inicia-se no cruzamento da Av. Boa Viagem com a Rua Bruno Veloso e segue para o sul por 410 metros até o início do enrocamento da praia da Boa Viagem (Figura 5).
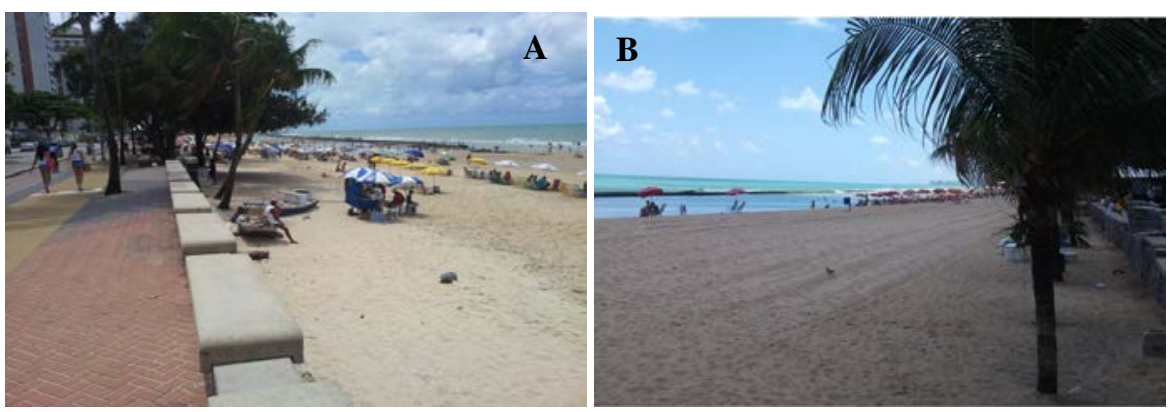

Figura 5. A) Apresenta a aproximação da Avenida Boa Viagem com a face praial. B) Apresenta a pós-praia aplainada em direção sul. Fonte: Da Silva (2013).

Este setor caracteriza-se por uma pós-praia próxima ao enrocamento reduzida a menos de 10 metros, com indicações claras de erosão costeira e com uma região de pós-praia de baixo declive. O Setor 4 apresenta a construção de enrocamento de pedras, com uma extensão de $2400 \mathrm{~m}$ (Figura 6). Este setor se caracteriza com indicações de vulnerabilidade à erosão costeira.
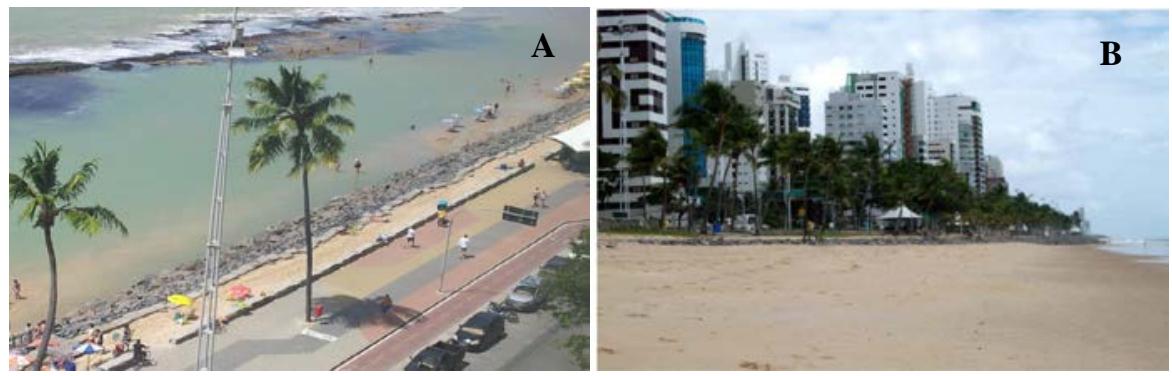

Figura 6. A) Apresenta o centro da construção do enrocamento onde a maré já chega a contenção da Av. Boa Viagem. B) Apresenta o final do enrocamento com a presença da região da pós-praia.

Fonte: Da Silva (2013).

O setor 5 ao sul da construção do enrocamento da praia da Boa Viagem, com uma extensão de $2.882 \mathrm{~m}$. Desta extensão $794 \mathrm{~m}$ pertencem a praia da Boa Viagem e 2088m a praia de Piedade (Figura 7). Este setor se caracteriza por uma face praial bem desenvolvida, uma praia arenosa em média $20 \mathrm{~m}$, sem indícios de erosão costeira. 
O setor 6 ao sul da praia de Piedade, com uma extensão de 2.022 m até o início do enrocamento da praia de Candeias (Figura 8). Observa-se neste setor uma face praial bem desenvolvida, porém na direção sul uma linha de costa menos retilínea que os setores anteriores. E no final do setor há um estreitamento da face praial. Como visto na descrição o município do Recife compreende 4 setores e parte do setor 5 , o município de Jaboatão dos Guararapes compreende 1 setor e parte do setor 5.

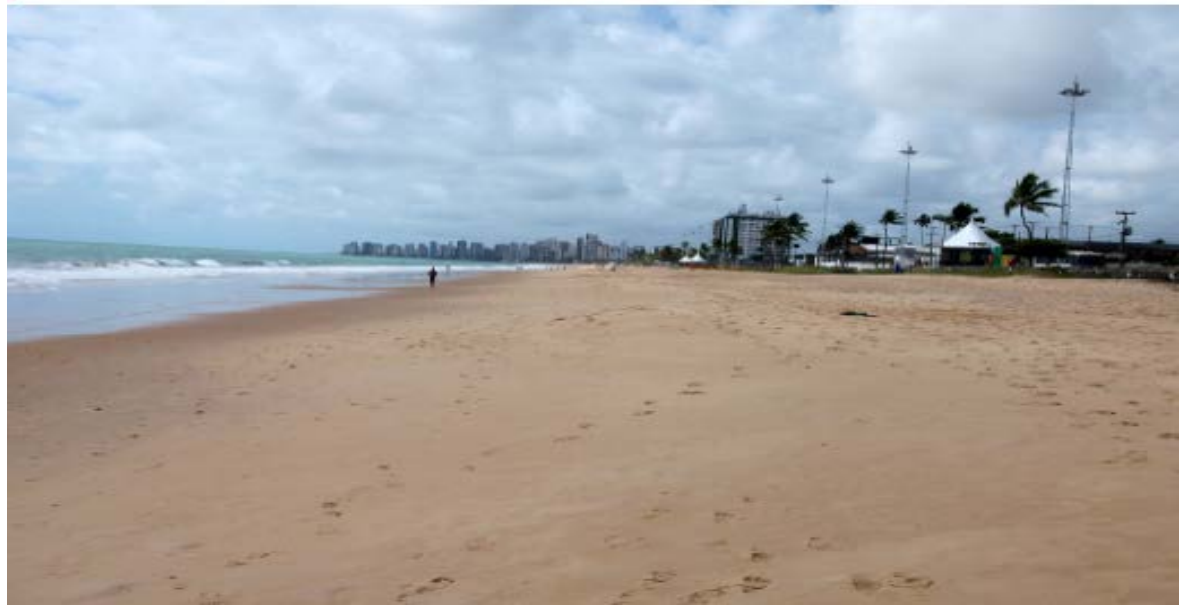

Figura 7. Na direção sul apresenta uma pós-praia desenvolvida.

Fonte: Da Silva (2013).
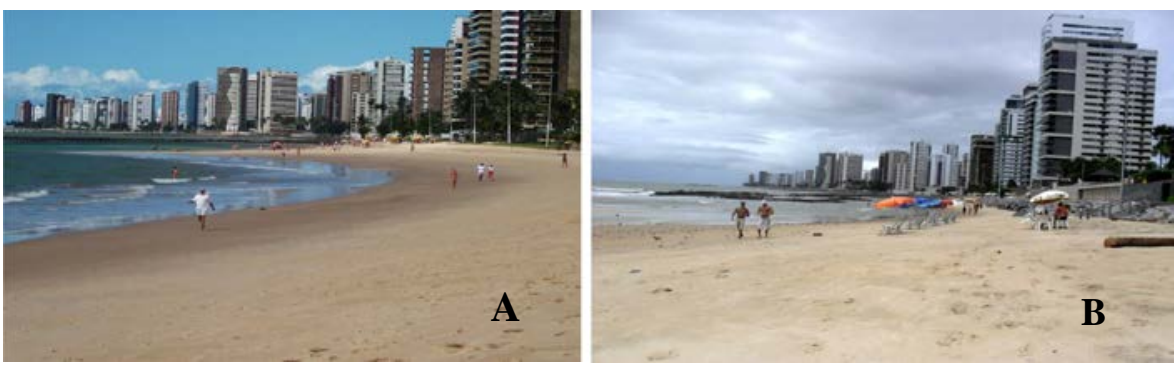

Figura 8. A) Observa-se a linha de costa curvilínea. B) Apresenta o final do setor antes do enrocamento entre a Praia de Piedade e Candeias.

Fonte: Da Silva (2013).

A Figura 9 apresenta os seis setores, detalhados nos parágrafos anteriores desta seção, onde se observou que o setor quatro tem a presença de enrocamentos, não sendo possível delimitar a linha de costa. Sendo assim, nas análises e discussões dos resultados serão considerados apenas cinco setores. 
Ainda poder-se-ia acrescentar outro setor na praia de Piedade ao norte da praia de Candeias, mas optou-se não mapear a linha de costa, pois ela encontra-se em contato direto com as construções e assim os problemas de erosão costeira estão presentes exigindo constantes obras de recuperação e manutenção.

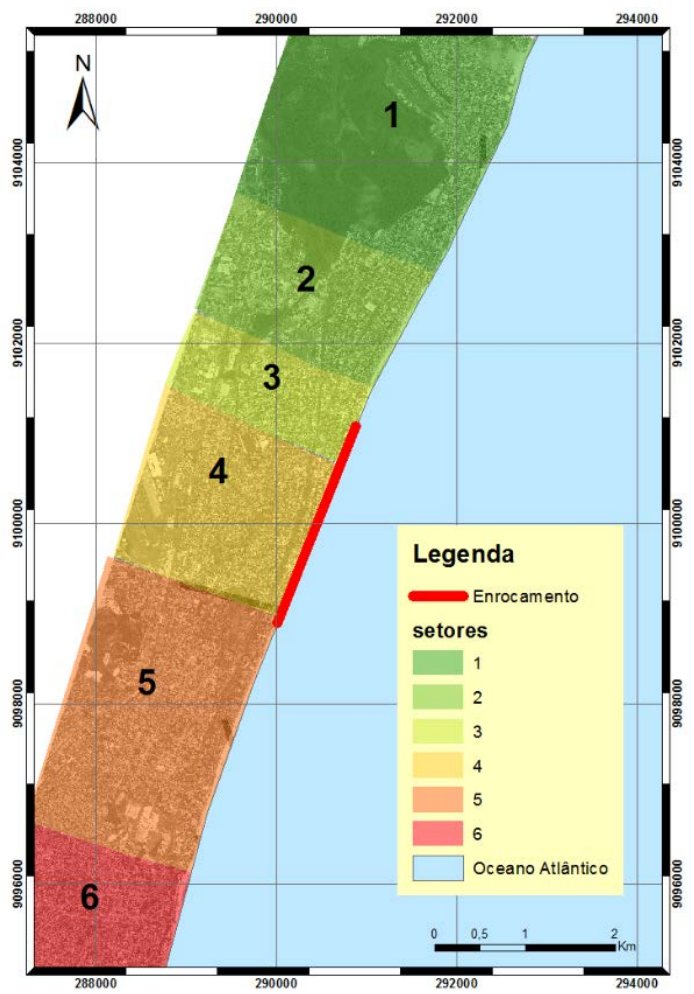

Figura 9. Todos os setores da área de estudo com destaque a área com enrocamento de pedras.

\section{Análise do Deslocamento da Linha de Costa}

A análise do deslocamento da linha de costa é gerada a partir de dados temporais da linha de costa (levantamentos que contém os dados vetoriais temporais). O cálculo da taxa de variação da linha de costa considerando os processos de avanços e recuos foi realizado automaticamente na extensão do software ArcGIS Detect Shifting Toolbox® (Bartelt, 2012). Isto foi feito através de distâncias de secções transversais entre as linhas de base, com intervalos de $10 \mathrm{~m}$. A Figura 10 apresenta um exemplo da linha de costa e transectos selecionados como base. Destaca-se que a linha de base utilizada como referencia é a do ano (2007) e as dos demais anos (2009, 2011 e 2012) foram utilizadas para geração dos transectos. 


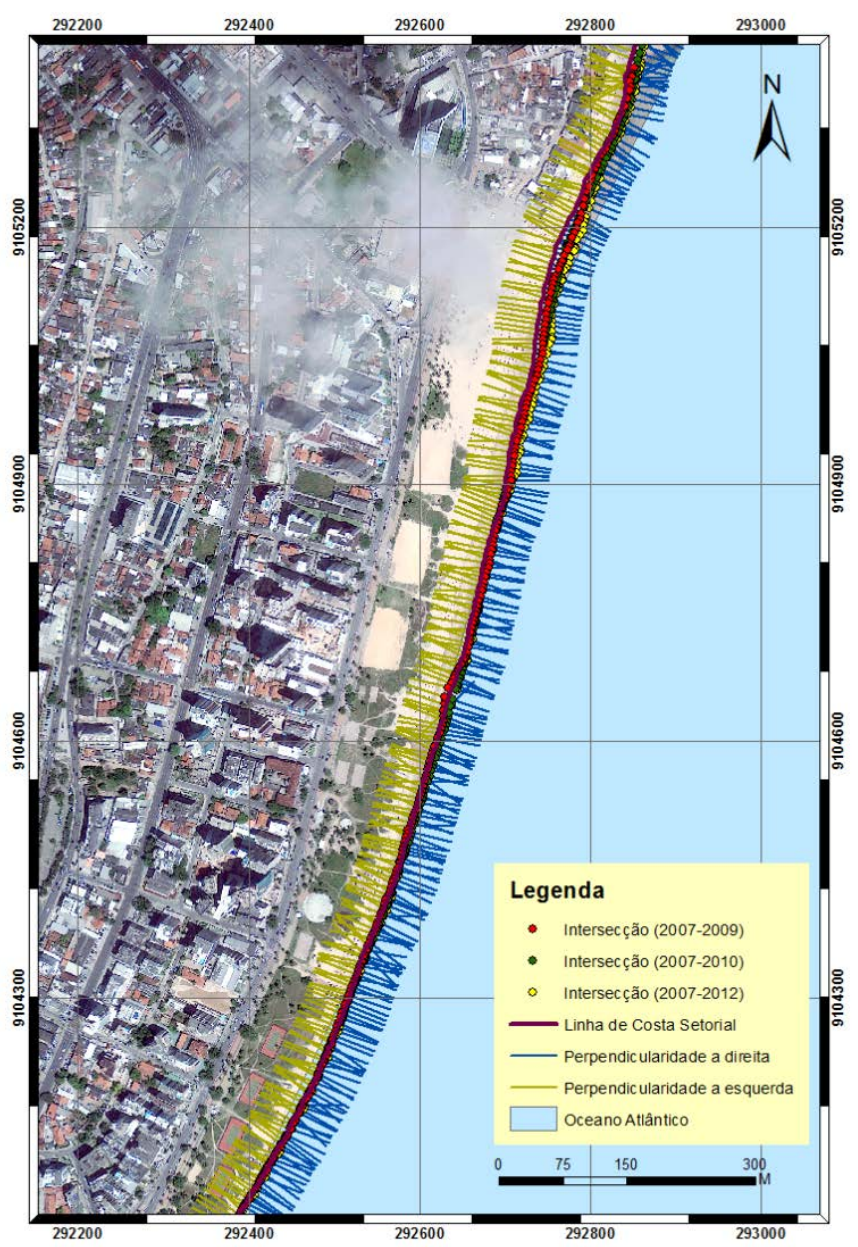

Figura 10. Transectos entre os pontos e perpendicularidades entre a linha de costa.

Resultado do deslocamento temporal da linha de costa

Após a caracterização da área de estudo são apresentado os resultados observados nos cinco setores, com exceção do setor 4, devido ser uma área sem a presença da linha de costa. Na Tabela 2 observam-se as taxas de variação do deslocamento da linha de costa (m/ano), deslocamentos máximos, deslocamentos mínimos e o desvio padrão dos anos 2009, 2010 e 2012. Os resultados são analisados convencionados a aferir a mudança da linha de costa, taxas negativas como de erosão (direção ao continente) e acresção as taxas positivas (direção ao mar). Para análise do deslocamento da linha de costa, destacando se houve recuo ou avanço na área costeira, 
consideraram-se as médias dos intervalos apresentados por Thieler e HammarKlose (2000), onde se destaca nos setores com erosão, pode apresentar vulnerabilidade muito alta $(<-2,0)$ ou alta $(-2,0$ a $-1,0)$; setores estáveis apresentam vulnerabilidade moderada $(-1,0$ a 1,0); setores recuperados ou com acreção pode apresentar vulnerabilidade baixa $(1,0$ a 2,0$)$ ou muito baixa $(>2,0)$.

Tabela 2

Taxa de Variação (m/Ano) do deslocamento da linha de costa Setorial

\begin{tabular}{cccccc}
\hline Setor & Ano & Média $(\mathrm{m})$ & $\begin{array}{c}\text { Deslocamento } \\
\text { Mínimo }(\mathrm{m})\end{array}$ & $\begin{array}{c}\text { Deslocamento } \\
\text { Máximo }(\mathrm{m})\end{array}$ & $\begin{array}{c}\text { Desvio } \\
\text { Padrão }(\mathrm{m})\end{array}$ \\
\hline \multirow{3}{*}{1} & $2007-2009$ & 0,62 & $-6,48$ & 9,61 & 3,15 \\
& $2007-2010$ & 0,79 & $-6,37$ & 9,76 & 2,41 \\
& $2007-2012$ & 0,86 & $-0,88$ & 9,95 & 1,93 \\
\hline \multirow{3}{*}{2} & $2007-2009$ & $-1,41$ & $-9,77$ & 1,05 & 2,05 \\
& $2007-2010$ & $-0,68$ & $-6,9$ & 2,83 & 2,36 \\
& $2007-2012$ & $-0,18$ & $-6,13$ & 5,45 & 3,03 \\
\hline \multirow{3}{*}{3} & $2007-2009$ & $-1,63$ & $-7,88$ & 1,92 & 2,35 \\
& $2007-2010$ & $-0,45$ & $-3,71$ & 2,51 & 1,45 \\
& $2007-2012$ & 0,03 & $-4,17$ & 5,7 & 2,67 \\
\hline \multirow{3}{*}{4} & - & - & - & - & - \\
\multirow{3}{*}{5} & $2007-2009$ & 0,54 & $-9,82$ & 8,46 & 3,35 \\
& $2007-2010$ & 0,83 & $-9,81$ & 9,71 & 4,78 \\
& $2007-2012$ & 0,79 & $-9,99$ & 10 & 5,19 \\
\hline \multirow{3}{*}{6} & $2007-2009$ & $-3,53$ & -10 & $-2,53$ & 2,97 \\
& $2007-2010$ & $-2,94$ & $-9,82$ & $-7,9$ & 0,74 \\
& $2007-2012$ & 0,59 & -10 & 10 & 4,13 \\
\hline
\end{tabular}

O setor 1 localizado na praia do Pina e parte norte da praia da Boa Viagem e o setor 5 localizado em Piedade apresentaram as médias anuais positivos na taxa de deslocamento da linha de costa no período analisado. Esse setor apresenta uma estabilidade na linha de costa por ter um ambiente praial bem desenvolvido, com uma face praial plana e extensa. O setor 2 localizado na praia da Boa Viagem apresentou as médias negativas na taxa de deslocamento da linha de costa no período analisado. Esse setor apresenta uma instabilidade na linha de costa por ter um ambiente praial menos desenvolvido e possuir uma tendência à erosão. O setor 3 (praia da Boa Viagem) e o setor 6 (praia de Piedade) apresentaram as médias negativas nas taxas de variação do deslocamento da linha de costa nos anos de 2009 e 2010, e as médias positivas nas taxas de variação do deslocamento da linha de costa no ano de 2012.

Nas variações dos deslocamentos mínimos da linha de costa observa-se que todos os setores apresentam uma tendência erosiva para os períodos analisados. Em relação ao deslocamento máximo dos setores, observa-se que os setores de 1 a 3 e 5 apresen- 
taram deslocamentos máximos positivos, sendo estes maiores deslocamentos observados (Tabela 2), nos valores de 9,76 (m/ano) e 9,95 (m/ano) para o setor 1 nos períodos 2007-2010 e 2007-2012, respectivamente e os valores de 9,71 (m/ano) e 10 (m/ano) para o setor 5 nos períodos 2007-2010 e 2007-2012, respectivamente. Entretanto, essa tendência de um maior deslocamento da linha de costa em direção ao oceano foi menor para os setores 2 e 3, apresentando valores maiores em 2007-2012 para ambos setores, para o setor 6 o deslocamento máximo foi negativo nos períodos de 2007-2009 e 2007-2010. Ressalta-se que o maior avanço da linha de costa em direção ao continente, quando ocorreu maior progradação foi durante o período de 2007-2012 nos setores 1,5 e 6 .

Em relação ao desvio padrão na taxa de deslocamento da linha de costa, os valores mais altos foram observados no setor 5 valores com 4,78 m e 5,19 m respectivamente para os períodos de 2007-2010 e 2007-2012. Em contrapartida o menor valor observado foi no setor 6 e no setor 3 os valores do desvio padrão são 0,74 m e 1,45 m, respectivamente, ambos para o período de 2007-2010. Ressalvando que estes setores representam as menores extensões nos seguimentos dos 5 setores, principalmente o setor 3, que apresentou uma diminuição na extensão do seu seguimento a partir do período de 2007-2009, devido a expansão do enrocamento para o norte na praia da Boa Viagem. Na Tabela 3 observa-se a distância em metros dos deslocamentos médios, mínimos e máximos nos períodos analisados.

Tabela 3

Distância da Variação (m/Ano) do deslocamento da linha de costa Setorial

\begin{tabular}{cccccc}
\hline Setor & Ano & $\begin{array}{c}\text { Média } \\
(\mathrm{m})\end{array}$ & $\begin{array}{c}\text { Deslocamento } \\
\text { Mínimo }(\mathrm{m})\end{array}$ & $\begin{array}{c}\text { Deslocamento } \\
\text { Máximo }(\mathrm{m})\end{array}$ & $\begin{array}{c}\text { Classificação das } \\
\text { taxas médias da } \\
\text { linha de costa }\end{array}$ \\
\hline \multirow{3}{*}{1} & $2007-2009$ & 1,24 & $-12,96$ & 19,22 & Baixa \\
& $2007-2010$ & 2,37 & $-19,11$ & 29,28 & Muito Baixa \\
& $2007-2012$ & 4,30 & $-4,40$ & 49,75 & Muito Baixa \\
\hline \multirow{3}{*}{2} & $2007-2009$ & $-2,83$ & $-19,54$ & 2,1 & Muito Alta \\
& $2007-2010$ & $-2,03$ & $-20,70$ & 8,49 & Muito Alta \\
& $2007-2012$ & $-0,91$ & $-30,65$ & 27,25 & Alta \\
\hline \multirow{3}{*}{3} & $2007-2009$ & $-3,27$ & $-15,76$ & 3,84 & Muito Alta \\
& $2007-2010$ & $-0,13$ & $-11,13$ & 7,53 & Moderada \\
& $2007-2012$ & 0,13 & $-20,85$ & 28,5 & Moderada \\
\hline \multirow{2}{*}{4} & - & - & - & - & - \\
\hline \multirow{2}{*}{5} & $2007-2009$ & 1,07 & $-19,64$ & 16,92 & Baixa \\
& $2007-2010$ & 2,45 & $-29,43$ & 29,13 & Muito Baixa \\
& $2007-2012$ & 3,97 & $-49,95$ & 50 & Muito Baixa \\
\hline \multirow{2}{*}{6} & $2007-2009$ & $-7,07$ & $-20,00$ & $-5,06$ & Muito Alta \\
& $2007-2010$ & $-8,82$ & $-29,46$ & $-23,7$ & Muito Alta \\
& $2007-2012$ & 1,93 & $-50,00$ & 50 & Baixa \\
\hline
\end{tabular}


Todos os valores do deslocamento médio da linha de costa no setor 1 e o setor 5 apresentam acreção em todos os períodos analisados. No setor 2 os valores médios apresentam erosão em todos os períodos. Nos setores 3 e 6 no período de 20072009 apresentam erosão, enquanto no período de 2007-2012 a tendência a acresção. Mas no período de 2007-2010, o setor 3 apresenta recuperação, enquanto o setor 6 ainda apresenta erosão. Observa-se, também, que o maior deslocamento médio em direção ao continente foi no setor 6 no período de 2007-2010 correspondendo um valor de -8,82 m, enquanto no setor 1 houve um deslocamento médio em direção ao oceano no período de 2007-2012 correspondendo um valor de 4,30 m. Para as distâncias mínimas foi observado que todos os setores apresentaram recuos da linha de costa com valores entre $-4 \mathrm{~m}$ e $-50 \mathrm{~m}$. O setor 1 apresentou o menor valor $-4,4 \mathrm{~m}$ no período de 2007-2012 e o maior deslocamento negativo (recuo da linha de costa) no setor 5 com o valor de $-50 \mathrm{~m}$ para o período de 2007-2012. Comparando o setor 6 , aos setores 2, 3 e 5 observa-se uma diminuição na taxa de deslocamento negativo durante o período de 2012.

Em relação às distâncias máximas dos setores, observa-se que os setores de 1 a 3 e 5 apresentaram deslocamentos máximos positivos, sendo estes maiores deslocamentos observados nos valores de 49,75 m e 50 m respectivamente para o setor 1 e para o setor 5 no período de 2007-2012. Entretanto essa tendência de um maior deslocamento da linha de costa em direção a costa foi menor para os setores 2 e 3 , principalmente no setor 6 onde o deslocamento máximo foi negativo para os períodos de 2007-2009 e 2007-2010, mas pode-se observar que no período de 2007-2012 a distância do deslocamento máximo tem o valor igual ao do setor 5 , sendo a distância maior da análise. A maior acresção da linha de costa em direção ao oceano, ocorreu nos setores 5 e 6 , no mesmo período.

\section{Conclusão}

Em uma análise temporal de cinco anos para as praias da Boa Viagem, Pina e Piedade foram possíveis verificar as mudanças que ocorrem ao longo da área costeira. Essas mudanças foram caracterizadas a partir de setores, onde foi possível identificar e quantificar os avanços, estabilidade, erosão, assim como atividades antrópicas. Considerando as informações da linha de costa do ano de 2007 como referência, foi possível analisar a evolução da linha de costa para os anos de 2009, 2010 e 2012, quantificando e analisando nos setores se havia acreção ou erosão.

De acordo com a Tabela 3, o Setor 1 (2007-2009), por exemplo, mostrou uma taxa de recuo considerada baixa, depois entre (2007-2010 e 2007-2012) permaneceu moderada embora com taxas diferentes, pois mostra a média correspondia a 1,24 m e 2,37 m, respectivamente a estes períodos. Em contrapartida o Setor 3 que apresenta parte com enrocamento em (2007-2009 mostrou uma taxa de recuo considerada muito alta, depois entre (2007-2010) a taxa mudou para moderada e no 
período (2007-2012) permaneceu como moderada. O Setor 6 observou-se que há uma recuperação da área pois nos períodos de (2007-2009) e (2007-2010) apresentaram um recuo muito alto, em (2007-2012) apresenta um recuo considerado baixo.

No monitoramento da linha de costa ao longo do tempo, observou-se que o aumento das obras de enrocamento de pedras tem causado sérios problemas de erosão costeira, na parte central da Praia da Boa viagem, a área com enrocamento, Setor 4, requer manutenção constante. Para este setor da praia, não foram calculadas as taxas da linha de costa. Os enrocamentos de pedras são construídos para proteger a costa no intuito de remover a energia das ondas e proteger as áreas urbanas de ressacas. Mas a falta de planejamento pode-se tornar um grande problema para as áreas urbanas que estão cada vez mais no espaço da área costeira. E por falta de dinâmica praial, o mar tende "invadir" as áreas urbanas, voltando ao seu espaço. Recomenda-se a continuidade do monitoramento da linha de costa para a área de estudo, uma vez que esta área apresenta um comportamento complexo na linha de costa como observado neste estudo.

\section{Bibliografia}

Almeida, H.R.R.C., (2008). "Séries temporais de imagens suborbitais e orbitais de alta resolução espacial na avaliação da morfodinâmica praial no município do Cabo de Santo Agostinho -PE”, Dissertação de conclusão de curso, Mestrado em Ciências Geodésicas, UFPE, 124 pp.

Araújo, M.C.B.; Souza, S.T.; Chagas, A.C.O.; Barbosa, S.C.T. e Costa, M.F., (2007). “Análise da Ocupação Urbana das Praias de Pernambuco, Brasil”, Revista da Gestão Costeira Integrada, 7(2), pp. 97-104.

Aureliano, J.T., (2000). "Balnealidade das praias de Pernambuco: O núcleo Metropolitano”, Dissertação de conclusão de curso, Mestrado em Gestão e Políticas Ambientais, UFPE, 113 pp.

Bartelt, S., (2012). "Manual do ArcCatalog: Detect Shifting Toolbox ${ }^{\circledR}$ ”.

Boak, E.H. e Turner, I. L. (2005). "Shoreline Definition and Detection: A Review", Journal of Coastal Research, 21(4), pp. 688-703.

Daniel, H., (2001). "Replenishment versus retreat: the cost of maintaining Delaware's beaches”, Ocean \& Coastal Management, 44, pp. 87-104.

Da Silva, L.M.; Gonçalves, R.M.; Farias, R.D. e Martins, T.L., (2012). "Deteç̧ão de mudanças antrópicas no ambiente praial em Boa Viagem - RecifePE”, IV Simpósio Brasileiro de Ciências Geodésicas e Tecnologias da Geoinformação, Recife - PE, pp. 1-7.

Da Silva, L.M., (2013). "Modelagem Fuzzy como subsídios para a espacialização da vulnerabilidade costeira à erosão", Dissertação de conclusão de curso, Mestrado em Ciências Geodésicas, UFPE, 164 pp. 
Da Silva, L.M.; Gonçalves, R. M.; Lira, M. M. S. e Pereira, P. S., (2013). "Modelagem fuzzy aplicada na detecção da vulnerabilidade à erosão costeira”, Boletim de Ciências Geodésicas, vol. 19, pp. 746-764.

Doody, J.P., (2001). "Shoreline management - conservation, management or restoration?”, National Coastal Consultants, pp. 407-419.

Emm, V.; Tsokos, A.; Kotsi, E., (2016). "Shoreline change detection and coastal erosion monitoring using digital processing of a time series of high spatial resolution remote sensing data”, Bulletin of the Geological Society of Greece, vol. L, pp. 1747-1755.

Gonçalves, R.M., Pacheco, A.D.P., Tanajura, E.L.X. e Da Silva, L.M., (2013), "Urbanização costeira e sombreamento na praia de Boa Viagem, RecifePE, Brasil”, Revista de Geografia Norte Grande, 54 (1), pp. 241-255.

Hapke, C. e Plant, N., (2010). "Predicting coastal cliff erosion using a Bayesian probabilistic model”, Journal of Marine Geology, 278, pp. 140-149.

Harley, M.D.; Turner, I. L.; Short, A.D. e Ranasinghe, R., (2011). “Assessment and integration of conventional, RTK-GPS and image-derived beach survey methods for daily to decadal coastal monitoring”. Journal of Coastal Engineering, 58, pp. 194-205.

King, C.A.M., (1959). “Beaches and Coasts”, Arnold, London, 403 pp.

Komar, P.D., (1998). “Beach processes and Sedimentation”, Englewood Cliffs, New Jersey, Pretice Hall, 544 p.

Lei de Gerenciamento Costeiro do Estado de Pernambuco. “Lei No 14. 258”, de 23 de dezembro de 2010.

Mallmann, D.L.B. e Araújo, T.C.M., (2010). "Vulnerabilidade do Litoral Sul de Pernambuco à erosão”, Tropical Oceanography, 38 (2), pp. 129-151.

Manso, V.A.V.; Coutinho, P.N.; Guerra, N.C. e Junior, C.F.A.S., (2006). "Erosão e Progradação do Litoral Brasileiro: Pernambuco”, Laboratório de Geologia e Geofísica Marinha - LGGM, Recife: Editorial da Universidade.

Mazzer, A. M.; Dillenburg, S.R. e Souza, C.R.G., (2008). "Proposta de método para análise de vulnerabilidade à erosão costeira no sudeste da ilha de Santa Catarina, Brasil”, Revista Brasileira de Geociências, 38 (2), pp. 278-294.

Mendonça, F.J.B., Gonçalves, R.M., Awange, J., Silva, L.M. e Gregório, M.N., (2014). “Temporal shoreline series analysis using GNSS”, Boletim de Ciências Geodésicas, 20 (3), pp. 711-729.

Morais, J.O.; Pinheiro, L.S.; Cavalcante, A.A.; Paula, D.P. e Silva, R.L., (2008). "Erosão Costeira em Praias Adjacentes às Desembocaduras Fluviais: O Caso de Pontal de Maceió, Ceará, Brasil”, Revista da Gestão Costeira Integrada, 8(2), pp. 61-76.

Muehe, D., (2006). “Erosão e progradação do litoral brasileiro”, Brasília: Ministério do Meio Ambiente. 
Neves, C.F. e Muehe, D., (2008). "Vulnerabilidade, impactos e adaptação a mudanças do clima: a zona costeira”, Parcerias Estratégicas, 27, 80 pp.

Raposeiro, P.D. e Ferreira, J.C.R., (2010). “A análise da vulnerabilidade e do risco de inundação como ferramenta de apoio à gestão dos territórios litorais sob pressão urbana”, Pluris: Planejamento urbano regional integrado $e$ sustentável, pp. 1-12.

Rocha, C.P.; Araújo, T.C.M. e Mendonça, F.J.B., (2008). “Aplicação de técnicas de posicionamento GPS tridimensional para localizar linhas de costa: estudo de caso na praia de Boa Viagem, Recife-PE, Brasil”, Revista da Gestão Costeira Integrada, 8 (2), pp. 127-137.

Ryabchuk, D.; Spiridonov, M.; Zhamoida, V.; Nesterova, E. e Sergeev, A., (2010). "Long term and short term coastal line changes of the Eastern Gulf of Finland: Problems of coastal erosion”, Journal Coastal Conser, Springer Science, pp. 1-10.

Seeber, G., (2003). "Satellite Geodesy: Foundations, Methods and Aplications”, Berlin-New York, in Walter de Gruyter. 2 nd revised edition, 589 pp.

Smith, R.A., (1991). "Beach resorts: A model of development evolution”. Landscape and Urban Planning, 21, pp. 189-210.

Thieler, E.R. e Hammar-Klose E. S., (2000). "National Assessment of Coastal Vulnerability to Sea-Level Rise: Preliminary Results for the U.S. Gulf of Mexico Coast”, U.S. Geological Survey, Woods Hole, Massachusetts. 